\title{
Assessing Antibiotic Residue Removal from Milk Using Biochar
}

\author{
M. Suguna Devakumari \\ Department of Agriculture, School of Agriculture and Biosciences, Karunya Institute of Technology and Sciences, \\ Karunya Nagar, Coimbatore-641 114, T.N., India \\ †Corresponding author: M. Suguna Devakumari; sugisathish@yahoo.com
}

Nat. Env. \& Poll. Tech. Website: www.neptjournal.com

Received: 27-04-2020

Revised: $21-05-2020$

Accepted: 04-06-2020

Key Words:

Biochar

Antibiotic residue

Prosopis

Rice husk

Coconut shell

\begin{abstract}
The aim of this study was to evaluate the antibiotic residue removal from milk using biochar. The milk samples were collected from the local milk distributors of Coimbatore city and screened for antibiotic residues by using 3-1 Dip Stick which can screen the three major antibiotic groups like Beta lactam, tetracycline and sulfonamide. The present investigation analyses the methodology for removing antibiotics from milk using Prosopis wood biochar, Rice husk biochar and Coconut shell biochar at different temperatures and contact time. The results revealed that Prosopis biochar of $0.2 \mathrm{~mm}$ sieve size at higher temperatures subjected to 60 minutes contact time performed better and removed the antibiotics from a maximum number of milk samples.
\end{abstract}

\section{INTRODUCTION}

The use of antibiotics therapy to treat and prevent udder infections in cows is a key component of mastitis control in many countries. Due to the widespread use of antibiotics for treatment of mastitis in dairy cows, much effort and concerns have been directed towards the proper management and monitoring of antibiotics usage in treatments in order to prevent contamination of raw milk. As the widespread use of antibiotics has created potential residue problems in milk and milk products that are consumed by the general public (Jones \& Seymour 1988, Oliver et al.1990). Because of the public health significance, milk and milk products contaminated with antibiotics beyond a given residue level, are considered unfit for human consumptions.

Antimicrobial resistance is a complex issue and a global threat. Therefore, the responsible use of antibiotics is absolutely necessary and regulation is needed. However, in countries like India, it is common practice to use antibiotics on healthy animals, in order to prevent disease and infection and to promote growth which paves way for the entry of antibiotics into dairy products and milk. Residual antibiotics in milk can seriously affect consumers' health causing allergic reactions and developing resistant strains. Antibiotic contamination in milk can also cause significant economic losses for producers and manufacturers of milk and milk products. Although antimicrobial drugs are useful for the treatment of human infections, their occurrence in milk causes adverse public health effects such as drug resistance and hypersensitivity that could be life-threatening (Khaskheli et al.2008, Nisha 2008)

Biochar is cheaper and chemically inert material causing no harm and also economically feasible method for removing antibiotics from contaminated milk. Adsorption is one of the most efficient means of limiting antibiotic contamination and displays advantages such as low cost, simple design and easy operation. The adsorption capacity of biochar depends on the biomass feedstock and the pyrolysis process because these factors influence biochar characteristics such as surface area, surface functional groups and porosity and can be altered easily to remove specific antibiotics present in milk (Mitchell et al. 2015, Liu et al. 2012).

In this study, antibiotic residues in raw milk samples were screened and the contaminated samples were treated with biochar to remove antibiotics through adsorption.

\section{METHODOLOGY}

Biochar produced by pyrolysis of three different plant sources Prosopis wood, coconut shell and rice husks are procured from Tamil Nadu Agricultural University. The biochar samples were pulverized using pestle and mortar and sieved with $2 \mathrm{~mm}$ sieve and $0.2 \mathrm{~mm}$ sieve to get 2 particle sizes of each biochar (Fig. 1). 


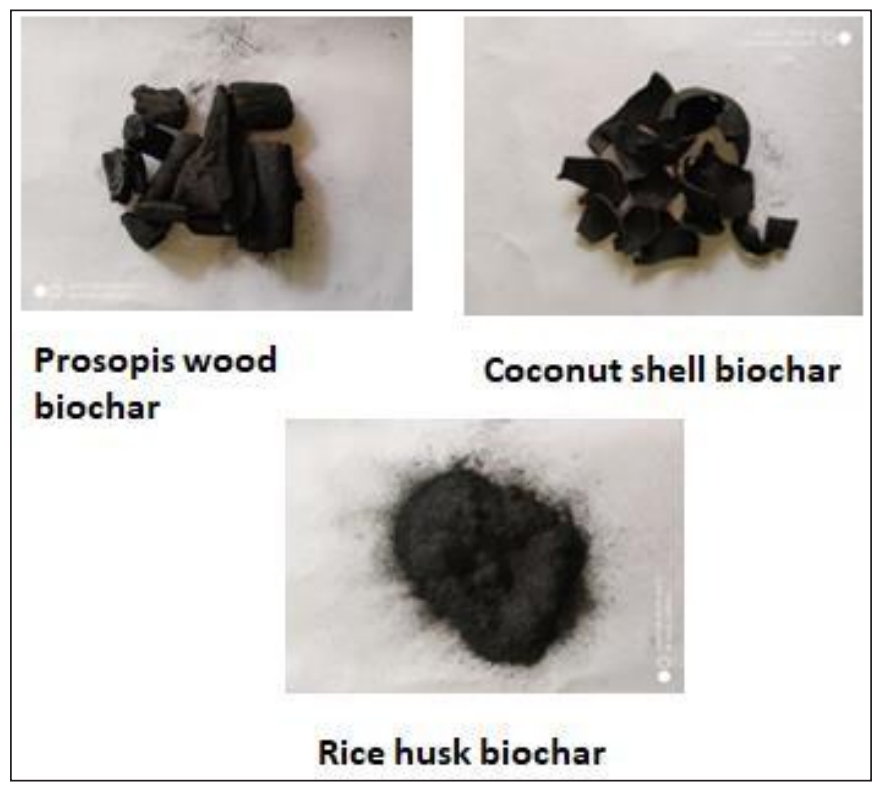

Fig.1: Biochar types used in the study.

Three separate glass columns, having an internal diameter of $1 \mathrm{~cm}$ and a length of $40 \mathrm{~cm}$, were packed with known weight $(25 \mathrm{~cm})$ of biochar from three different plant origins (Prosopis wood, Coconut shell and Rice husk) as shown in Fig. 2.

Initially, milk sample free from antibiotic residue is allowed to pass through the biochar packed column to remove the air spaces in the adsorbent. $20 \mathrm{~mL}$ of whole milk samples tested positive for antibiotics was added separately through each column. The columns were maintained at three different temperatures $\left(30^{\circ} \mathrm{C}, 40^{\circ} \mathrm{C}\right.$ and $\left.60^{\circ} \mathrm{C}\right)$ by placing inside the water bath. The milk samples were allowed to be in contact with the biochar in the glass column for two different contact periods (30 minutes and 60 minutes) and then drained out and tested for antibiotic residue presence using the 3-1 Dip Stick which can screen the three major antibiotic groups

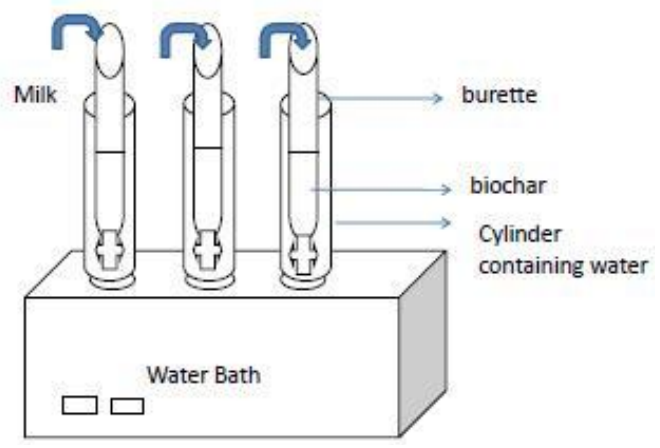

Fig. 2: Laboratory set up of the experiment. like Beta lactam, Tetracycline \& Sulfonamide. The antibiotic positive samples were noted.

\section{RESULTS AND DISCUSSION}

The three types of biochar (Prosopis wood, coconut shell and rice husks) were characterised for their physicochemical properties as shown in Table 1.

Among the three types of biochar, Prosopis wood biochar of $0.2 \mathrm{~mm}$ size performed better in removing the antibiotic residues from milk samples Table 2 .

As the contact time with the adsorbent (biochar) increased the removal of antibiotic residue was observed in more number of samples. Similarly when the temperature of the column increased the removal rate of antibiotic residue was found to be in more number of samples (Fig. 3-5).

Table 1: Characteristics of the biochar types used in the study.

\begin{tabular}{|c|c|c|c|}
\hline Parameters & $\begin{array}{l}\text { Rice } \\
\text { husk } \\
\text { Biochar }\end{array}$ & $\begin{array}{l}\text { Coconut } \\
\text { shell } \\
\text { biochar }\end{array}$ & $\begin{array}{l}\text { Prosopis } \\
\text { Biochar }\end{array}$ \\
\hline Temperature of pyrolysis ${ }^{\circ} \mathrm{C}$ & 300 & 300 & 300 \\
\hline Biochar yield \% & 32 & 45 & 34 \\
\hline $\mathrm{pH}$ & 7.48 & 8.66 & 8.73 \\
\hline $\mathrm{EC} \mathrm{dSm}^{-1}$ & 0.41 & 0.98 & 2.20 \\
\hline Bulk density g. $\mathrm{cm}^{-3}$ & 0.86 & 0.54 & 0.34 \\
\hline CEC C mol p ${ }^{+} \mathrm{kg}^{-1}$ & 12.6 & 19.9 & 14.3 \\
\hline Ash content $\%$ & 8.6 & 7.4 & 7.2 \\
\hline Total C \% & 42 & 34.4 & 67 \\
\hline
\end{tabular}


Table 2: Number of positive samples (samples containing antibiotics) after the biochar adsorption.

\begin{tabular}{|c|c|c|c|c|c|c|c|}
\hline \multirow[t]{3}{*}{ Biochar type and size } & \multicolumn{7}{|c|}{ Number of positive samples containing antibiotic residues } \\
\hline & \multirow{2}{*}{$\begin{array}{l}\text { Initial no. of positive } \\
\text { samples (Control) }\end{array}$} & \multicolumn{2}{|c|}{$25^{\circ} \mathrm{C}$ Temperature } & \multicolumn{2}{|c|}{$40^{\circ} \mathrm{C}$ Temperature } & \multicolumn{2}{|c|}{$60^{\circ} \mathrm{C}$ Temperature } \\
\hline & & $\begin{array}{l}\text { Contact time } \\
30 \mathrm{~min}\end{array}$ & $\begin{array}{l}\text { Contact time } \\
60 \mathrm{~min}\end{array}$ & $\begin{array}{l}\text { Contact time } \\
30 \mathrm{~min}\end{array}$ & $\begin{array}{l}\text { Contact time } \\
60 \mathrm{~min}\end{array}$ & $\begin{array}{l}\text { Contact time } \\
30 \mathrm{~min}\end{array}$ & $\begin{array}{l}\text { Contact time } \\
60 \mathrm{~min}\end{array}$ \\
\hline Prosopis $0.2 \mathrm{~mm}$ & 6 & 3 & 2 & 2 & 0 & 0 & 0 \\
\hline Prosopis $2 \mathrm{~mm}$ & 6 & 4 & 3 & 3 & 1 & 1 & 1 \\
\hline Rice husk $0.2 \mathrm{~mm}$ & 6 & 4 & 3 & 3 & 2 & 2 & 2 \\
\hline Rice husk $2 \mathrm{~mm}$ & 6 & 4 & 4 & 4 & 2 & 2 & 2 \\
\hline Coconut shell $2 \mathrm{~mm}$ & 6 & 4 & 3 & 3 & 1 & 1 & 1 \\
\hline Coconut shell $0.2 \mathrm{~mm}$ & 6 & 4 & 4 & 2 & 1 & 1 & 1 \\
\hline
\end{tabular}

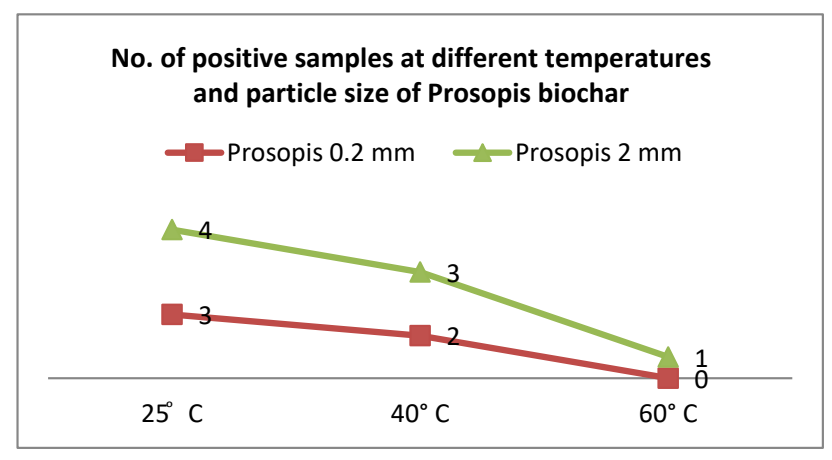

\begin{tabular}{|llll|}
\hline Type \& Size & $25^{\circ} \mathrm{C}$ & $40^{\circ} \mathrm{C}$ & $60^{\circ} \mathrm{C}$ \\
\hline Prosopis $0.2 \mathrm{~mm}$ & 3 & 2 & 0 \\
Prosopis $2 \mathrm{~mm}$ & 4 & 3 & 1 \\
\hline
\end{tabular}

Fig. 3: Number of positive samples at different temperatures and particle size of Prosopis biochar.

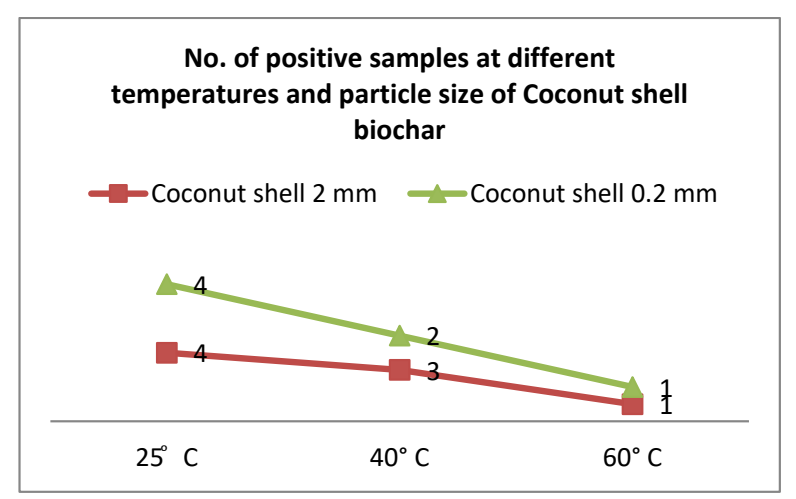

\begin{tabular}{|llll|}
\hline Type \& Size & $25^{\circ} \mathrm{C}$ & $40^{\circ} \mathrm{C}$ & $60^{\circ} \mathrm{C}$ \\
\hline Coconut shell $2 \mathrm{~mm}$ & 4 & 3 & 1 \\
Coconut shell $0.2 \mathrm{~mm}$ & 4 & 2 & 1 \\
\hline
\end{tabular}

Fig. 5: Number of positive samples at different temperatures and particle size of Coconut shell biochar.

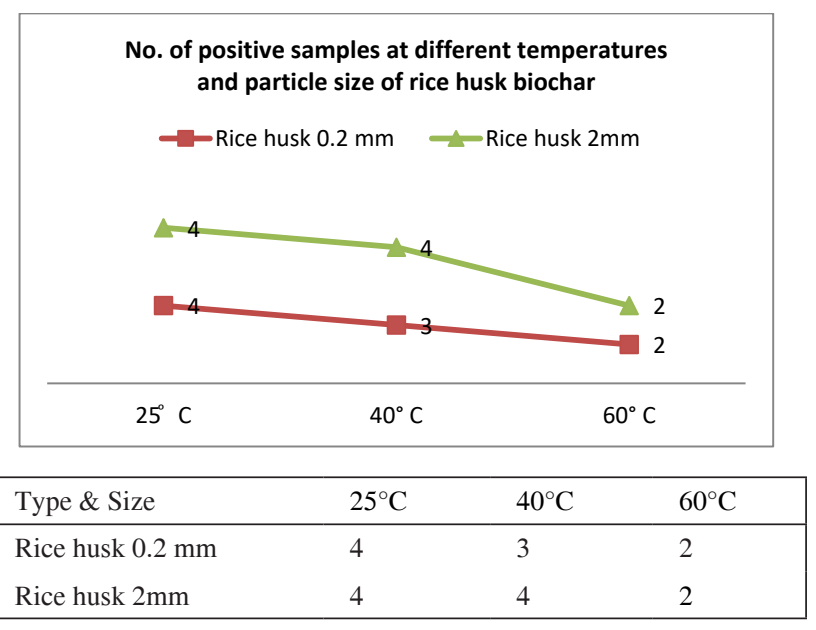

Fig. 4: Number of positive samples at different temperatures and particle size of rice husk biochar.

The above graphs infer that small particle size and higher temperature of the adsorbent (biochar) favours removal of antibiotic residue from milk samples. Among the type of biochar used Prosopis performed better in removing the antibiotic residues. So biochar could be used as an adsorbent for antibiotic residues in milk. This is in accordance with the previous report that the biochar pyrolyzed at 500 and $700^{\circ} \mathrm{C}$ were relatively high efficient at removing tetracycline from an aqueous solution (Wang et al. 2017).

\section{CONCLUSION}

Overall, biochar derived from pyrolyzing Prosopis wood offers a promising option for a low-cost method of removing antibiotic residue from milk and the other biochar produced from rice husk and coconut shell also removed the antibiotic from more number of positive samples. Moreover higher temperature and increased contact time with the adsorbent increased the antibiotic removal efficiency. 


\section{REFERENCES}

Jones, G. M. and Seymour, E.H. 1988. Cowside antibiotic residues testing. Journal of Dairy Science, 71: 1691-1699.

Khaskheli, M., Malik, R. S., Arain, M. A., Soomro, A. H. and Arain, H.H. 2008. Detection of $\square-$ lactam antibiotic residues in market milk. Pakistan Journal of Nutrition., 7: 682-685.

Liu, P., Liu, W.J., Jiang, H., Chen, J.J., Li, W.W. and Yu, H.Q. 2012. Modification of biochar derived from fast pyrolysis of biomass and its application in removal of tetracycline from aqueous solution. Bioresour. Technol., 121: 235-40.
Mitchell, S.M., Subbiah, M., Ullman, J. L., Frear, C. and Call, D.R. 2015. Evaluation of 27 different biochars for potential sequestration of antibiotic residues in food animal production environments. J. Environ. Chem. Eng., 3(1): 162-9.

Nisha, A.R. 2008. Antibiotic residues - a global health hazard. Veterinary World, 1: 375-377.

Oliver, S. P., Maki, J. L. and Dowlen, H. H. 1990. Antibiotic residues in milk following antimicrobial therapy during lactation. Journal of Food Protection., 53: 693-696.

Wang, H., Chu, Y., Fang, C., Huang, F., Song, Y. and Xue, X. 2017. Sorption of tetracycline on biochar derived from rice straw under different temperatures. PLoS ONE, 12(8): e0182776. 